\title{
Findings from the Young Children's Computer Inventory Project
}

Gerald A. Knezek

University of North Texas

USA

Keiko T. Miyashita

Tokyo Institute of Technology

Japan

\author{
Takashi Sakamoto \\ National Centre for \\ University Entrance \\ Examinations \\ Japan
}

\begin{abstract}
Questionnaire responses were gathered from grade 1-4 students attending schools in Japan, Mexico, and the USA during 1990-1993. Student dispositions were assessed in six areas: Computer Importance, Computer Enjoyment, Motivation/Persistence, Study Habits, Empathy and Creative Tendencies. Nineteen major findings are grouped into categories. Three examples of findings are: early computer exposure has a strong positive impact on children's Computer Enjoyment and perceptions of Computer Importance, gender differences at the first grade level were found only for Empathy and the tendency for ratings to decline with increased age (novelty effect) was stronger for several other school related dispositions than for Computer Importance, and was not found for Computer Enjoyment.
\end{abstract}

Main conference themes: social issues

Educational areas: primary education

Study topics:

Secondary keywords: computing, culture, research 


\section{INTRODUCTION}

The Young Children's Computer Inventory (YCCI) project was started in 1990 as a longitudinal study of childhood computing in school. The project was designed to provide findings from students in grades 1-3 to complement two other multinational studies (ITEC \& IEA CompEd) addressing the effects of information technology on students at higher grade levels [1,2]. The project was conceptualized primarily as a quantitative policy study rather than a test of a psychological theory.

\section{Project rationale}

The YCCI project began as a Japan-United States (US) collaborative effort to search for three kinds of evidence related to the use of computers in primary schools

- Evidence that early computer exposure in school can have a positive, lasting impact on children's attitudes toward computers.

- Evidence that computers can have a positive, lasting effect on learning related dispositions such as creative tendencies, motivation and study habits.

- Evidence that computer use by primary school students does not have significant negative side effects such as loss of touch with reality or diminished concern for the welfare of fellow human beings.

With respect to the first goal previous studies had indicated that computer access can improve attitudes toward computers for students of high school and college ages. A Soviet-US study of 8-12 year old children also supported this claim [3]. However, no previous studies were known to have documented this effect for children as young as grade 1 in school.

The second goal was strongly emphasized in the US Teachers supported the early introduction of computers and previous research provided encouraging results [4], but pressure continued to mount to document the educational effectiveness of computers in school.

The third goal was emphasized more strongly in Japan. Computers were purposely not introduced into public elementary schools during most of the 1980s [5], while both the 'light and dark sides' of increased computer exposure were being contemplated [6].

The initial research plan was to compare quantitative data on attitudes among students at schools newly equipped with computers in Japan with attitudes at comparable Japanese schools not possessing computers using time synchronized data from the US as a crosscultural control. Mexico was added as a new research initiative for 1992 in order to provide a third cultural perspective. 


\section{Instrument}

The Young Children's Computer Inventory (YCCI) instrument was developed to carry out this research [7]. It is a 48-item Likert type selfrating questionnaire measuring six psychological dispositions (prevailing attitudes): Computer Importance, Computer Enjoyment, Motivation/Persistence, Study Habits, Empathy and Creative Tendencies. The overall internal consistency reliability of the scale is 0.92 when utilizing the 44 items shown in the Annex. Subscale reliabilities range from a low of 0.66 to a high of 0.85 when data from all language/culture administrations are combined [8].

With respect to overall project goals Computer Importance and Computer Enjoyment served as measurement indicators for Goal 1, while Motivation/Persistence, Study Habits and Creative Tendencies served as measurement indicators for Goal 2. Empathy was the measurement indicator for Goal 3.

\section{Subjects}

As shown in Table 1, 5517 student responses from 46 school administrations were included in the study. Many of the same schools provided data for three or four consecutive years which means that the actual number of unique subjects was much smaller than the 5517 questionnaire returns. Approximately 3000 students completed surveys one or more times during the four years of the project. The data for the 46 school administrations was gathered from 26 separate schools.

\section{Procedure}

All questionnaires at the Japan sites and the US schools for Japanese dependants were completed in Japanese by the children, with their parents, at home. For English and Spanish administrations in the US questionnaires were completed under teacher supervision during school time in 1990, 1991 and 1992. For 1993 the two public schools administered questionnaires in school, while a private school sent questionnaires home to be completed under parental supervision. Mexico administrations were completed in Spanish under teacher supervision during school time.

Rates for completion of usable questionnaires in the Japanese language varied by school from approximately $50 \%$ to $99 \%$ with all public schools in Japan returning more than $90 \%$. For the US and Mexico the completion rate resulting from school administration is estimated to be at least $90 \%$ of the potential student sample. Typically all students not absent on the day of administration completed questionnaires and typically all teachers in a given grade agreed to have their students complete questionnaires. 
Table 1 Young Children's Computer Inventory schools and subjects

\begin{tabular}{llllllll}
\hline & $\begin{array}{l}\text { Grade } \\
\text { Level }\end{array}$ & $\begin{array}{l}\text { Japan } \\
\text { Schools }\end{array}$ & $\begin{array}{l}\text { Japanese USA } \\
\text { in USA }\end{array}$ & Schools & $\begin{array}{l}\text { Hispanic } \\
\text { in USA }\end{array}$ & $\begin{array}{l}\text { Mexico } \\
\text { Schools }\end{array}$ & $\begin{array}{l}\text { Total Sch. } \\
\text { (Subjects) }\end{array}$ \\
\hline 1990 & $\begin{array}{l}1-2 \\
(99)\end{array}$ & $\begin{array}{l}1 \\
(51)\end{array}$ & $\begin{array}{l}1 \\
(112)\end{array}$ & 1 & - & - & 3 \\
1991 & $\begin{array}{l}1-2 \\
(734)\end{array}$ & 6 & - & 8 & - & - & $\begin{array}{l}14 \\
(262)\end{array}$ \\
1992 & $1-3$ & 6 & 1 & 7 & 5 & 2 & 21 \\
& & $(1236)$ & $(59)$ & $(1072)$ & $(247)$ & $(422)$ & $(3036)$ \\
1993 & $1-4$ & 2 & 2 & 3 & 1 & - & 8 \\
& & $(200)$ & $(251)$ & $(266)$ & $(61)$ & & $(778)$ \\
\hline \multirow{2}{*}{ Total } & & 15 & 4 & 19 & 6 & 2 & 46 \\
& & $(2269)$ & $(361)$ & $(2157)$ & $(308)$ & $(422)$ & $(5517)$ \\
\hline
\end{tabular}

\section{Chronology of Results}

The YCCI was pilot tested in the US and Japan during 1990, administered to first and second grade students in Japan and the US during March 1991, administered to first, second and third grade students in Japan, the US and Mexico during March-April 1992, and administered to first, second, third and fourth grade students in Japan and the US during March-April 1993. This section contains the major results from each year of the study.

1990 Results: For the pilot test year of the study major findings were:

- American computer using first and second grade students in Texas were more positive than Japanese-in-Japan noncomputer using students on their Attitudes Toward Computers.

- American students were less Empathetic than their Japanese counterparts; American students were more positive on Study Habits.

- No significant differences were found in the areas of Motivation/Persistence or Creative Tendencies.

An additional finding was that Texas based Japanese students typically fell between the Japanese-in-Japan students and the traditional Texas students on the attributes measured [9]. 
1991 Results: Major findings for the first full scale research year were:

- Japanese first and second grade children who used computers, tended to like computers more than children who did not use computers.

- There was no evidence that computer use had a negative impact on children's Empathy.

- There was no strong evidence that one or two years of computer use in school had a positive impact on children's Motivation/Persistence, Study Habits or Creative Tendencies.

An additional finding was that any of several different types of computer experiences (CAI alone, mixed CAI and Logo programming, mixed word processing and graphics production) could produce a positive effect on children's attitudes toward computers. Results for 1991 also reconfirmed the homogenous nature of the public education environment in Japan. There were no significant differences among urban, suburban and rural children's scores for any of the areas measured [10].

1992 Results: The second full scale research year focused on longitudinal trends in the data among first, second and third grade students in Japan, Mexico and the US Computer access was found to raise Computer Enjoyment and perceived Computer Importance. Computer access was not found to lower Empathy. No strong $(\mathrm{p}<0.01)$ influence was found on Motivation/Persistence, Study Habits or Creative Tendencies, and gender differences emerged only for Empathy (females were more empathetic). Students' prevailing psychological tendencies (their dispositions) were generally quite positive in the four noncomputing areas measured and dispositions among all students tended to decline from the first through the third grades in school. However, no novelty effect (the tendency for ratings to decline with increasing age or over time) was found for Computer Enjoyment. An unanticipated outcome was that bilingual Hispanic students in the US frequently reported dispositions more positive than either the students in Mexico or the native English speaking students in the US Differential item response characteristics for Japan and US led to caution in drawing additional conclusions from direct comparisons among average responses for the three nations [11].

1993 Results: For the third research year the study was refocused to address several specific follow-up questions. Six schools representing a cross-section of the 21 sites used in the previous year were retained and two new schools in Hawaii were added to the group. All schools in the sample provided data from grades 1-4. 
Major findings were:

- Reconfirmation that computer exposure has a positive impact on Computer Enjoyment and Computer Importance.

- Confirmation that computer exposure can have a positive $(\mathrm{p}<0.01)$ impact on Study Habits and Motivation/Persistence (when students with four years of computer exposure are included).

- Confirmation that Japanese students living in Japan, Hawaii and Texas have similar dispositions regardless of residence, as do native English speaking students in Texas and Hawaii.

- New probable causal relations in the direction of:

a) higher Creative Tendencies leading to higher perceived Computer Importance;

b) greater Computer Enjoyment leading to higher perceived Computer Importance;

c) greater Empathy leading to higher Motivation/Persistence [12].

\section{SUMMARY OF FINDINGS}

Findings from the four years 1990-1993 are summarized in the following nineteen points grouped within six categories:

\section{Instrumentation}

1. Young children in grades 1-3 have stable $(r=0.90)$ psychological dispositions which can be measured by selfreport inventories.

\section{Effects Due to Computer Exposure}

2. Early initial computer exposure (grade 1) in school increases Computer Enjoyment by approximately two-thirds of a standard deviation.

3. Early computer exposure in school increases perceived Computer Importance by approximately one-half standard deviation.

4. Early computer exposure (up to four years) in school does not appear to have a negative effect on Empathy.

5. Early computer exposure (up to four years) in school does not appear to have a positive effect on Creative Tendencies.

6. Three or four years of computer exposure in primary school can have a measurable positive impact on Motivation/Persistence and Study Habits. 


\section{Effects Due to Time/Maturation}

7. Children's selfreported values on Motivation/Persistence, Study Habits, Empathy and Creativity tend to decline as they progress from grades 1-3.

8. There appears to be a weak tendency for this decline to take place with regard to Computer Importance (novelty effect).

9. This decline does not normally take place with regard to Computer Enjoyment which tends to remain high or increase as the children grow older.

10. Effects 1-5, 7-9 are robust across several different types of computer applications (robustness unknown for \#6).

11. Effects 7-9 are not necessarily true for children emigrating to a new (foreign) culture.

\section{Effects Due to Gender}

12. No gender differences were found for Computer Importance, Computer Enjoyment, Motivation/Persistence, Study Habits or Creative Tendencies at the first grade level; and no consistent differences by gender were found at the second and third grade level.
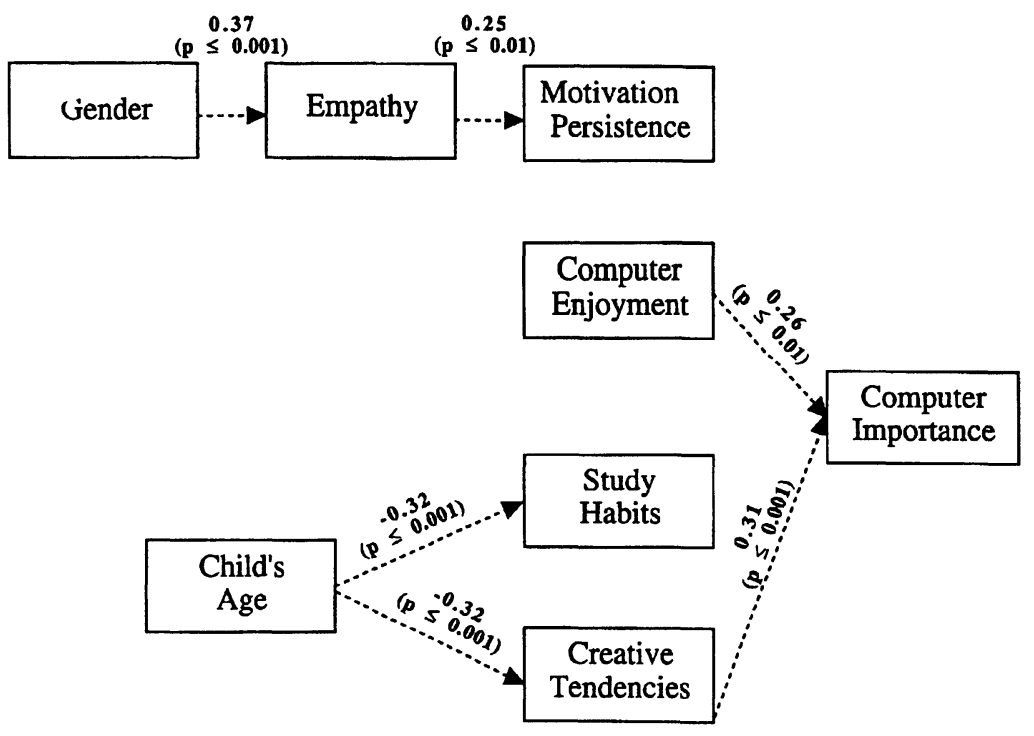

Fig. 1 Path coefficients for background variables and psychological dispositions based on 1991-1992 paired US data $(n=166)$

13. Females were more Empathetic than males at the first, second and third grade levels. 
14. Effects 12-13 are true for English speaking US students in Texas, native language Japanese students in Japan and Spanish speaking natives in Mexico.

\section{Directionality of Selected Effects (see Fig. 1)}

15. Increased Computer Enjoyment appears to lead to higher ratings on Computer Importance.

16. Higher Creative Tendencies appear to lead to higher student perceptions of Computer Importance.

\section{Influence of Culture (see Fig. 2 below)}

17. The effect of early computer exposure in school on Computer Enjoyment appears to be largely universal, culture free.

18. Computer Importance appears to be influenced by both exposure and culture.

19. Study Habits appear to be strongly influenced by culture.

More detailed descriptions of these and other results can be found in the YCCI Final Report [12]. This 74 page booklet is available from the Texas Center for Educational Technology, PO Box 13857, Denton, Texas, USA 76203.

\section{CONCLUSION}

Much has been discovered over the past four years about how computer use in primary school influences the psychological dispositions of children. The Young Children's Computer Inventory project (YCCI) has been able to provide findings [12] complementary to the sixteen nation Information Technology in Education and Children Project (ITEC) [1] and the twenty-one system International Studies in Educational Achievement (IEA) Computers in Education Project (CompEd) [2], as planned. Nevertheless the YCCI project is just a beginning. It is hoped that the findings will provide a solid foundation for future research in this area. 


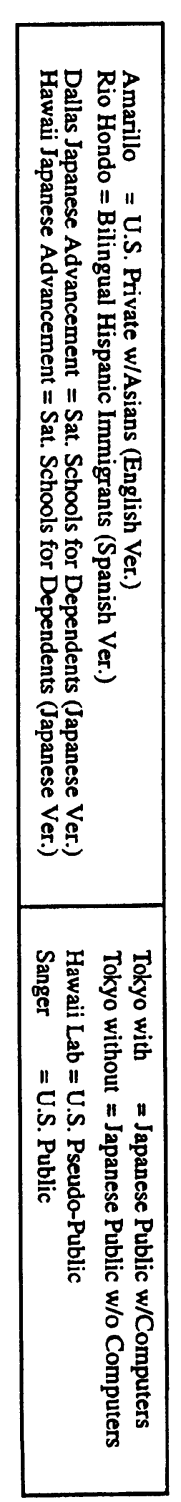

$N$
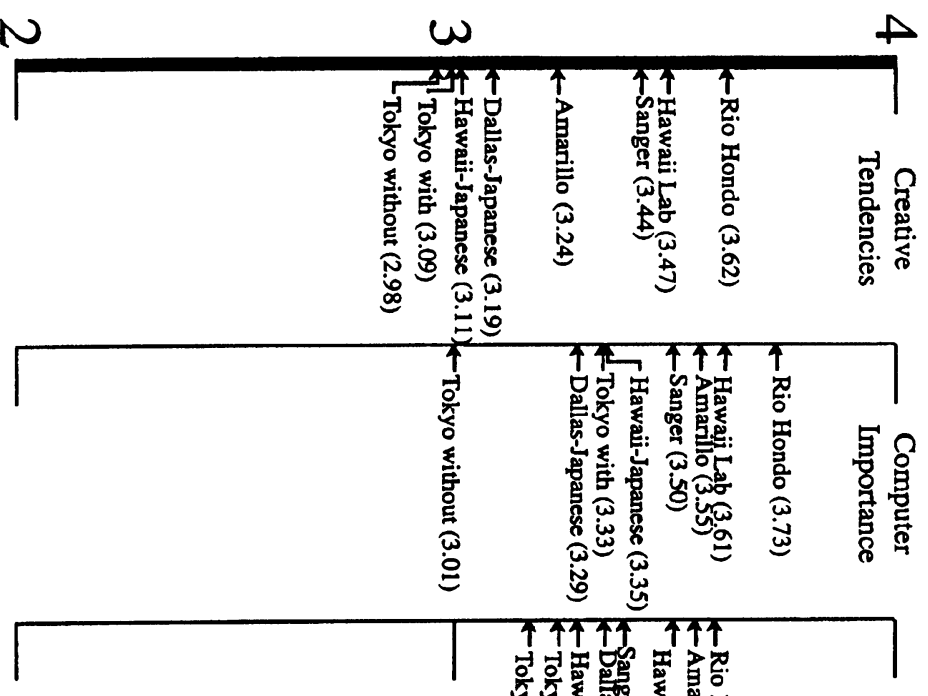

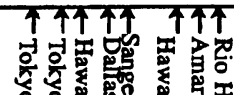

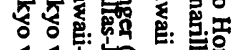

E. E.

ब它

涳气

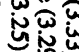

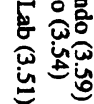

营
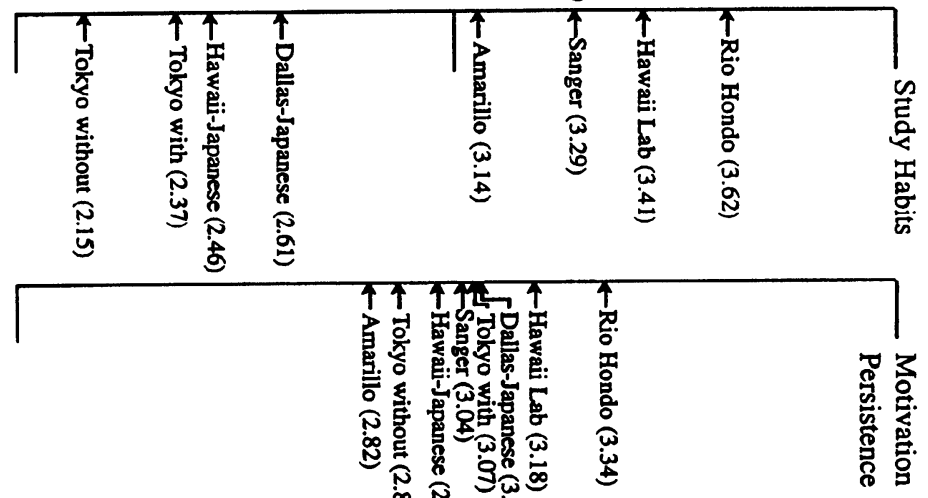

要 递
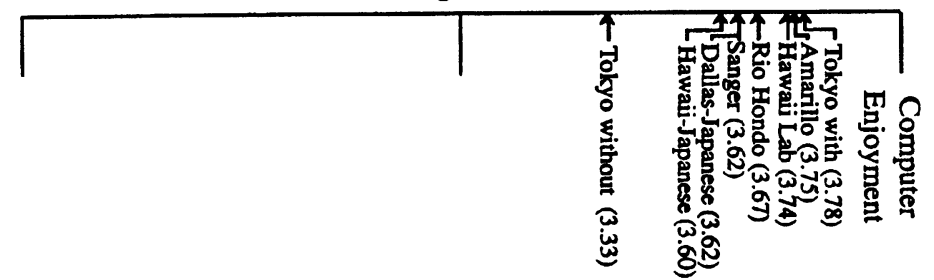


\section{REFERENCES}

1. Collis, B. (1993) The ITEC Project: Information Technology in Education of Children. Final Report of Phase 1. University of Twente, Netherlands: UNESCO Division of Higher Education.

2. Pelgrum, W.J. \& Plomp, T. (1993) The IEA Study of Computers in Education: Implementation of an Innovation in 21 Education Systems. Oxford: Pergamon Press.

3. Martin, D., Heller, R. and Mahmoud, E. (1992) American and Soviet children's attitudes toward computers. Journal of Educational Computing Research, 8 (2) pp. 155-185.

4. Clements, D.H. (1991) Enhancement of creativity in computer environments. American Educational Research Journal, 28 (1) pp. 173-187.

5. Knezek, G., Miyashita, K. and Sakamoto, T. (1990) Computers in education: Japan versus the United States, in Computers in Education. (eds McDowell, A. and McDougall, C.), North-Holland: Elsevier Science Publishers B. V., pp. 775-780.

6. National Council on Educational Reform (1986, April 23) Summary of Second Report on Educational Reform. Tokyo: Government of Japan.

7. Miyashita, K. \& Knezek, G. (1992) The Young Children's Computer Inventory: A Likert scale for assessing attitudes related to computers in instruction. Journal of Computing in Childhood Education, 3, pp. 63-72.

8. Knezek, G. \& Miyashita, K. (1993) Handbook for the Young Children's Computer Inventory. Denton, TX: Texas Center for Educational Technology.

9. Knezek, G. \& Miyashita, K. (1991) Computer-related attitudes of primary school students in Japan and the U.S.A. Educational Technology Research (Japan), 14, pp. 17-23.

10. Miyashita, K. (1991) Influence of computer use on attitudes toward computers, motivation to study, empathy, and creativity among Japanese firstand second-grade children. Doctoral Dissertation, University of North Texas. 
11. Knezek, G.A., Miyashita, K.T., \& Sakamoto, T. (1993) Cross-cultural similarities in attitudes toward computers and the implications for teacher education. Journal of Information Technology for Teacher Education (Netherlands), 2 (2) pp. 193-204.

12. Knezek, G.A., Miyashita, K.T., and Sakamoto, T. (1994) Young Children's Computer Inventory Final Report. Denton, TX: Texas Center for Educational Technology.

\section{ANNEX}

\section{YCCI Items Ordered by Strength of Factor Loadings}

\section{Computer Importance}

9 I can learn many things when I use a computer.

12 I believe that it is very important for me to learn how to use a computer. $62 \mathrm{I}$

8 I know that computers give me opportunities to learn many new things. $.60 \mathrm{I}$

3 I will be able to get a good job if I learn how to use a computer.

11 I believe the more often teachers use computers, the more I will enjoy school. .45 I

6 I would work harder if I could use computers more often.

10 I enjoy lessons on the computer.

\section{Computer Enjoyment}

$1 \mathrm{I}$ enjoy doing jobs which use a computer. $.59 \mathrm{~J}$

$2^{*} \mathrm{I}$ am tired of using the computer.

10 I enjoy lessons on the computer.

5 I enjoy computer games very much.

$4 \mathrm{I}$ concentrate on a computer when I use one.

\section{Motivation/Persistence}

16 If I do not understand a problem, I will not stop working on it. $\quad .53 \mathrm{M}$

22 I think about many ways to solve a difficult problem and I never give up. $\quad .48 \mathrm{M}$

23 I never forget to do my homework. $\quad .43 \mathrm{M}$

21 I enjoy working on a difficult problem. $\quad .42 \mathrm{M}$

17 When I don't understand something, I keep working until I find the answer. $.31 \mathrm{M}$

15 I study by myself without anyone forcing me to study. $.27 \mathrm{M}$

\section{Study Habits}

24 I like to work out problems which I can use in my life every day. $.57 \mathrm{~S}$

18 I review my lessons every day $.52 \mathrm{~S}$

19 I try to finish whatever I begin.

20 Sometimes, I change my study habits. 
15 I study by myself without anyone forcing me to study.

25 If I do not understand my teacher, I ask him/her questions.

\section{Empathy}

30 I worry when I see a sad friend.

26 I feel sad when I see a child crying.

29 I feel sad when I see old people alone.

27 I sometimes cry when I see a sad play or movie.

35 I feel happy when I see a friend smiling.

28 I get angry when I see a friend who is treated badly.

$.48 \mathrm{E}$

31 I feel very happy when I listen to a song I like.

32 I do not like to see a child play alone, without a friend.

33 I feel sad when I see an animal hurt.

\section{Creative Tendencies}

42 I find different kinds of materials when the ones I have do not work. $\quad .58 \mathrm{C}$

40 I create many unique things.

44 I make a plan before I start to solve a problem.

36 I examine unusual things.

39 I tend to consider various ways of thinking.

37 I find new things to play with or to study, without any help.

43 I examine unknown issues to try to understand them.

38 When I think of a new thing, I apply what I have learned before.

46 I invent new methods when one way does not work.

41 I do things by myself without depending upon others.

45 I invent games and play them with friends.

47 I choose my own way without imitating methods of others.

* Reversed Item 